\title{
What Countries Select More Experienced Leaders? The PolEx Measure of Political Experience
}

\author{
Alexander Baturo $^{1}$ (D) and Johan A. Elkink ${ }^{2 *}$ (D) \\ ${ }^{1}$ School of Law and Government, Dublin City University, Dublin, Ireland and ${ }^{2}$ School of Politics and International Relations, \\ University College Dublin, Dublin, Ireland \\ *Corresponding author. E-mail: jos.elkink@ucd.ie
}

(Received 15 January 2020; revised 26 November 2020; accepted 28 February 2021; first published online 14 May 2021)

\begin{abstract}
How can one assess which countries select more experienced leaders for the highest office? There is wide variation in prior career paths of national leaders within, and even more so between, regime types. It is therefore challenging to obtain a truly comparative measure of political experience; empirical studies have to rely on proxies instead. This article proposes PolEx, a measure of political experience that abstracts away from the details of career paths and generalizes based on the duration, quality and breadth of an individual's experience in politics. The analysis draws on a novel data set of around 2,000 leaders from 1950 to 2017 and uses a Bayesian latent variable model to estimate PolEx. The article illustrates how the new measure can be used comparatively to assess whether democracies select more experienced leaders. The authors find that while on average they do, the difference with non-democracies has declined dramatically since the early 2000s. Future research may leverage PolEx to investigate the role of prior political experience in, for example, policy making and crisis management.
\end{abstract}

Keywords: political leaders; political selection; political experience; political careers; democracy and dictatorship

One of the central concepts in the study of political leadership, particularly in international relations, is individual experience (Bak and Palmer 2010; Horowitz, McDermott and Stam 2005; Potter 2007). More experienced leaders are less likely to be tested by adversaries and are often found to handle international crises more competently (for example, Gelpi and Grieco 2001). If the controversial 25 July 2019 phone conversation between Donald Trump and Ukrainian President Volodymyr Zelensky - both political outsiders prior to assuming office - is any evidence, less experienced leaders may also be found wanting in their knowledge of diplomatic practice. ${ }^{1}$ As the former foreign minister of Russia (1998-2004) Igor Ivanov noted, 'a "newcomer" in international politics is usually harder to work with: the lack of experience often translates into inconsistent and unpredictable behavior; it leads to subjective, emotional and at times erroneous decisions ...' (cited in Englund 2016).

We propose a new empirical measure of political experience at the time of selection into office. Our statistical approach differs from expert qualitative assessments as well as from studies that rely on particular proxies to account for experience, such as leaders' age (Bak and Palmer 2010; Horowitz, McDermott and Stam 2005), time in office (Gelpi and Grieco 2001; Potter 2007) or type of prior career (Horowitz, McDermott and Stam 2005), or that equate specific experience with competence (Yu and Jong-A-Pin 2016). Instead, we fit a Bayesian latent variable model on a range of experience-related indicators to estimate a new measure of political

\footnotetext{
${ }^{1}$ See www.whitehouse.gov/wp-content/uploads/2019/09/Unclassified09.2019.pdf, 28 September 2019.

( The Author(s), 2021. Published by Cambridge University Press. This is an Open Access article, distributed under the terms of the Creative Commons Attribution licence (http://creativecommons.org/licenses/by/4.0/), which permits unrestricted re-use, distribution, and reproduction in any medium, provided the original work is properly cited.
} 
experience, PolEx (together with associated measures of uncertainty). We provide our estimates for 1,949 national leaders around the world from 1950 to 2017. Our measure accounts for length (years in politics), breadth (experience in formal and informal posts) and quality (types of positions).

Finally, we demonstrate the use of this new measure by investigating whether democracies select more experienced leaders than dictatorships. This is not only intrinsically interesting; it also has implications for international security, if we contrast an apparent rise of outsiders across the democratic world with more experienced leadership in countries such as China or Russia.

\section{What Makes a Political Leader Experienced?}

Generally speaking, experience is a multifaceted and nebulous term because it not only depends on age or the type of positions occupied, but also on various activities and events, as well as the individual's ability to learn from such events. A political leader may be competent across a wide range of activities, including negotiation, mentoring, organization, persuasion, strategy and public relations. These skills are acquired in a wide range of different contexts, including social and professional, political and non-political contexts. Different leaders will therefore have built up their arsenal of skills across different experiences in life, moderated by their ability to learn and other innate traits.

Can political experience be measured? We believe that, all things being equal, important political skills should be on average more developed among individuals who have held senior political posts, or held them longer. For instance, to underline President George H. W. Bush's (1989-93) level of experience, Horowitz, McDermott and Stam $(2005,668)$ point out that he was a 'director of the Central Intelligence Agency, an ambassador, and a vice president'. We can look at an individual's political biography and make an informed guess about his or her level of experience in politics.

A key challenge associated with identifying relevant prior experience is to ensure that a measurement remains valid across different regimes. While the manner in which one acquires political experience might be very different in a parliamentary democracy than it is in a military junta, we nevertheless want to be able to compare levels of experience across all regimes. Democracies may attract more educated leaders (Besley and Reynal-Querol 2011), while dictatorships may be led by people with non-political backgrounds, such as from the military. Clearly, individuals with traits that conform to the norms of their regime will find it easier to progress their political careers. In order to be able to generalize, however, we focus on political experience that took place explicitly and primarily in formal politics, rather than general life experience or leadership experience in the military or corporate sector, for example. We call this a prior-experience approach to political experience.

International relations research often uses age as an alternative proxy for experience (Bak and Palmer 2010), an approach we refer to as age-experience. Horowitz, McDermott and Stam (2005, $664,667)$ point out that older leaders have more experience and more credibility. However, the youngest leader of an EU country (32 in 2019), Sebastian Kurz of Austria, had served as foreign minister and a member of parliament for four years prior to his chancellorship, while former US President Donald Trump was 70 years old when he entered the White House but had no prior political experience.

Another common proxy is education-experience. For example, Besley and Reynal-Querol (2011) argue that better education leads to more competent leaders, and demonstrate that democracies select more educated leaders than non-democracies. However, a leader with little education but years of active engagement in the party will have significantly more relevant experience than one who has a professor background, with limited experience outside of academia.

More commonly than age or education, time in office may be used as an explicit proxy for political experience (Gelpi and Grieco 2001; Horowitz, McDermott and Stam 2005; Potter 2007). However, a focus on tenure-experience ignores prior experience and cannot explain why different regimes select leaders with different levels of experience in the first place. 
While the approaches discussed above may account for general levels of experience, experience may also be more domain specific (Yu and Jong-A-Pin 2016). For example, a minister of finance might have domain-experience in the finance sector. Making generic comparisons between countries, across regimes and over decades requires a formulation of political experience that is less idiosyncratic.

In summary, there is a significant amount of conceptual stretching and proxying for experience and related concepts of age, competence and tenure in office. We focus on experience in actual politics, prior-experience, before becoming a national leader.

\section{The Data on Leaders' Political Experience}

To measure the political experience of leaders across the world, we begin with the Cursus Honorum data (Baturo 2016). We expand the coverage to include more than 450 additional political leaders in office before and after the range of these data, in 1950-59 and 2010-17. The resulting data set includes 1,949 individuals in office from 1 January 1950 to 31 December 2017.

Our goal is to account for the length and breadth of individuals' involvement in politics, as well as the quality of such involvement. A key indicator of the length of experience is the number of years in formal politics. This includes years of public service, for instance as a member of parliament, minister, governor or mayor. The number of years in politics is relatively straightforward to measure in democratic regimes, provided the relevant biographical data are available. For the majority of non-democratic leaders, it requires judgement as to what constitutes service in formal politics and what the relevant positions are in a particular dictatorship. For illustration, consider $\mathrm{Hu}$ Jintao of China (2003-12) who has 21 years of experience. In $1982 \mathrm{Hu}$ was selected as a promising young cadre for rapid promotion and became an alternate member of the Central Committee as well as the secretary of the Communist Youth League Central Committee (Ewing 2003, 21). Prior to 1982 he held a series of engineering jobs and served as party secretary in regional construction departments (Ewing 2003, 20). However, in the context of a party regime, his career prior to 1982 was more akin to that of a civil servant. Only when he became the secretary of the Communist Youth League did his political career properly begin. Subsequently, he served as a provincial party secretary in two regions, and then joined the Politburo Standing Committee. While Hu's experience is different from that of his peers in democracies, being a provincial party secretary is akin to regional governor, and sitting on a Politburo Standing Committee functionally resembles a powerful ministerial post in a democracy.

Not all politically relevant experience consists of holding formal posts. Future leaders participate in politics as political party organizers; they also participate in electoral campaigns and acquire political experience in non-political posts. Therefore, the second key variable, Total Years in Politics, relaxes the requirement of serving in formal posts and also includes years in political campaigns, years as an opposition leader, years with an active party membership and any other politics-related activity.

Experience in politics is not only about the length of service. The quality and breadth of such experience matter too. Figure 1 displays descriptive statistics about politically relevant posts the leaders have held in the past, separately for democracies and dictatorships. Democratic leaders are more likely to hold portfolios of the minister of environment, the economy or local government, or intergovernmental bodies. Dictators are more likely to have served as ministers of trade or public works, or served in the politburo, security agencies or as diplomats. Below we leverage these data to estimate latent scores of experience, PolEx.

\section{The Latent Variable Model to Estimate PolEx}

While we have a number of indicators of experience in politics, it is unclear how these add up to a single experience score. How do we weight each indicator? How much does formal experience 


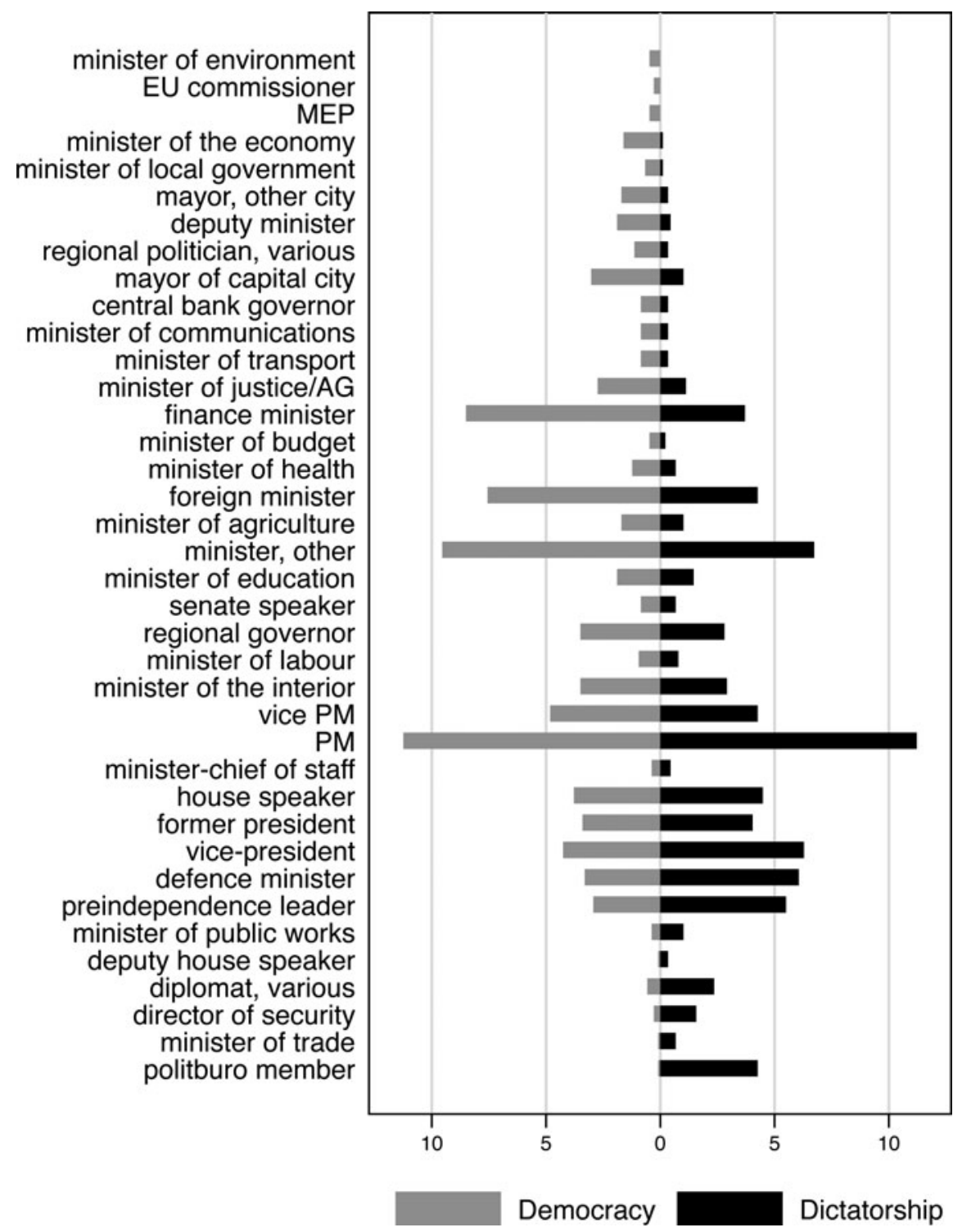

Figure 1. Prior political posts of leaders

Note: categories report the percentage of leaders with experience in particular posts prior to the highest office, sorted by relative differences between democratic and nondemocratic leaders. Categories do not add up to 100 per cent because leaders may occupy more than one post. For ease of presentation, the party leader/opposition leader/MP category is not included in the figure (21 per cent and 6 per cent in democracy and dictatorship, respectively).

count, relative to being 'on the ground' as a party activist? How much more experience does a former minister of foreign affairs have than a former minister of railroads? We address these questions by estimating a latent variable model to represent political experience, of which our various indicators are the observed implications.

Our model is different in important ways from comparable measurement models such as Treier and Jackman's (2008) assessment of democracy. Democracies share a range of characteristics, and the more these are present, the more likely it can be classified as a democracy. Yet the type of political experience varies significantly between leaders. One individual may have 


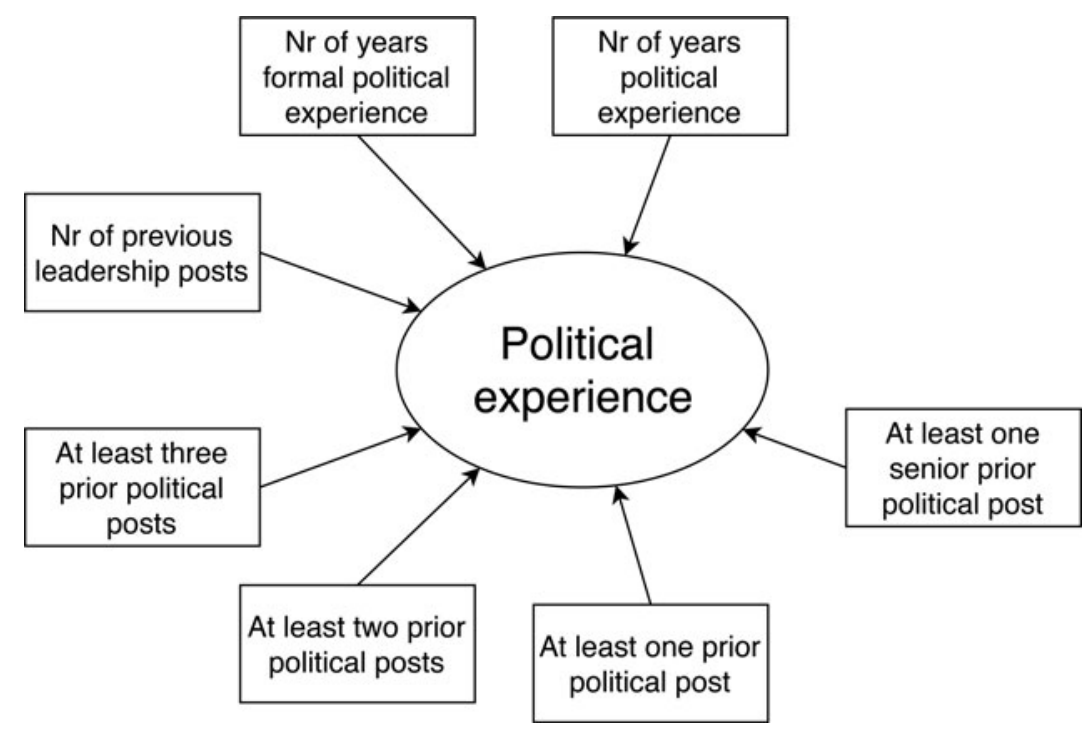

Figure 2. Measurement model of political experience

Note: measurement model specification of political experience, where squares represent observable, constitutive indicators of a latent construct, political experience.

experience as a deputy party leader, moving on to a junior minister role, to then become minister of finance and eventually the leader. Another person may reach the summit of power through an entirely different trajectory. Both might be similarly experienced overall. ${ }^{2}$

To avoid negative correlations between different types of experience due to mutual exclusivity of posts for the same individual at the same time, we aggregate posts into broad categories. We group all posts as either general political posts (see Figure 1 for a full list) or senior political posts and ministerial positions. We create a set of dummy variables taking the value of 1 if the individual occupied at least one, two, or three of the general posts, respectively, as well as a dummy indicating whether the individual occupied any of the senior posts. In addition, we include two variables counting the number of years of political experience - one for formal posts only and another more broadly defined - as well as a variable counting the number of times an individual has served as the national leader in the past. The diagram in Figure 2 outlines our measurement model specification. While individuals' career trajectories will differ, more experienced leaders will have held more posts, for longer, at more senior levels. Reducing the model to generic count variables and dummies allows us to estimate the latent variable model in a similar vein as Treier and Jackman (2008).

Aside from the estimation issues caused by the mutual exclusivity of different posts at the same time, this aggregation also maximizes the validity and comparability across regimes by raising the level of abstraction (Sartori 1970). The length of experience, the number of senior posts and the number of political posts - whatever these posts might be - on average should generate a valid cross-regime measurement. Anything else makes comparing experience by drawing from observational biographical data across regimes close to impossible. While the richness of experience between different national leaders is important and interesting, incorporating that richness makes it infeasible to measure political experience across regime types. Even though detailed

\footnotetext{
${ }^{2}$ This complication relates to the distinction between formative and reflective measurement models in the psychology and marketing literatures (Curtis and Jackson 1962; Diamantopoulos and Winklhofer 2001). See the Appendix for a more detailed discussion.
} 
types of offices and pathways cannot be seen from our measure, on average, high scores should correspond to higher levels of political experience.

We estimate PolEx using a Bayesian framework that allows us to obtain full posterior information on uncertainty for each individual score. Our model can be seen as a set of simultaneous regression equations, where the same latent variable explains the various indicator variables.

Because it is reasonable to assume that an individual's initial experience will be more significant than later additional years, we apply an inverse hyperbolic sine transformation - akin to a logarithmic transformation - on the three count variables. For the transformed count variables, we assume a normal distribution, while for the dummy variables we use a logistic specification. Each equation contains a discrimination parameter, with a prior $\beta_{1} \sim \Gamma(2,1)$ and a difficulty parameter with prior $\beta_{0} \sim N(0,1){ }^{3}$ For example, for the experience in years indicator we have:

$$
E Y_{i}^{*} \sim N\left(\beta_{1, E Y}\left(\gamma_{i}-\beta_{0, E Y}\right), \sigma_{E Y}\right)
$$

with $E Y^{\star}$ the observed experience in years, after the inverse hyperbolic transformation. The latent variable itself has a prior distribution of $\gamma \sim N(0,1)$. This follows the two-parameter logistic formulation of the item response theory model (Glockner-Rist and Hoijtink 2003), which is equivalent to a factor analysis model with binary or mixed responses (Quinn 2004). As in other applications in political science, the focus is on the latent variable scores for each observation, as opposed to the discrimination parameters that are the focus in psychometric applications (Clinton, Jackman and Rivers 2004). The model is estimated using the No-U-Turn Sampler algorithm (Carpenter et al. 2017), using eight chains of 20,000 iterations, of which 4,000 are discarded as a warm-up. ${ }^{4}$

Table 1 provides estimates of the discrimination and difficulty parameters. Difficulty parameters capture the extent to which, on average, leaders obtain a high level of experience on the particular indicator. Discrimination parameters, equivalent to factor loadings, capture the extent to which items are able to separate experienced and inexperienced leaders, but they cannot be directly compared between those for continuous variables and those for binary variables. To compare the relative importance of component variables, we can visualize the predicted values on the component variables given the latent variable score based on item response curves, which are presented in Figure 3.

All those who are scored as having above-average experience at the time of entering office tend to have had at least one prior political post. In turn, those with higher levels of experience also typically tend to have had a senior post or ministry. Having had multiple prior posts is less common. Among those at the highest levels of PolEx there is only just over a 60 per cent chance of having had three prior political posts. We also observe a strong relationship between PolEx and years of experience in formal and informal politics.

As a test of face validity, Figure 4 maps the PolEx scores of all leaders in the world in 2017, while Figure 5 provides additional detail on the most and least experienced leaders in the world in 2017. In both cases, leaders in office in 2017 are included, while their level of experience at the time they came to office is assessed. The results are intuitive as we can distinguish between experienced leaders such as Xi Jinping of China and inexperienced leaders such as Trump of the US.

\section{Regime Type and the Experience of Political Leaders}

The PolEx scores allow us to address a research question posed earlier: do democracies select more politically experienced leaders? Figure 6 reveals that over time and on average, democracies outperform dictatorships. However, the stark differences visible until the mid-1980s have been

\footnotetext{
${ }^{3}$ Using a gamma prior ensures positive coefficients, such that the latent variable captures experience rather than inexperience. Quinn (2004) and Clinton et al. (2004) implement similar constraints.

${ }^{4}$ The Gelman-Rubin convergence statistics range from $\hat{R}=0.9995$ to $\hat{R}=1.0014$, which indicates convergence.
} 
Table 1. Parameter Estimates and Relative Importance of Component Variables

\begin{tabular}{lcr}
\hline & Discrimination $\left(\beta_{1}\right)$ & Difficulty $\left(\beta_{0}\right)$ \\
\hline Nr of years experience & $1.127(0.025)$ & $-2.712(0.065)$ \\
Nr of years formal experience & $1.197(0.027)$ & $-2.142(0.055)$ \\
One prior political post & $2.352(0.136)$ & $-0.927(0.050)$ \\
Prior top post or ministry & $1.194(0.087)$ & $0.535(0.053)$ \\
Two prior political posts & $1.316(0.122)$ & $1.292(0.090)$ \\
Three prior political posts & $2.339(0.120)$ & $1.728(0.297)$ \\
Nr of previous times in office & $0.094(0.158)$ & $-1.486(0.008)$ \\
\hline
\end{tabular}

Note: standard errors for the model parameters in parentheses.
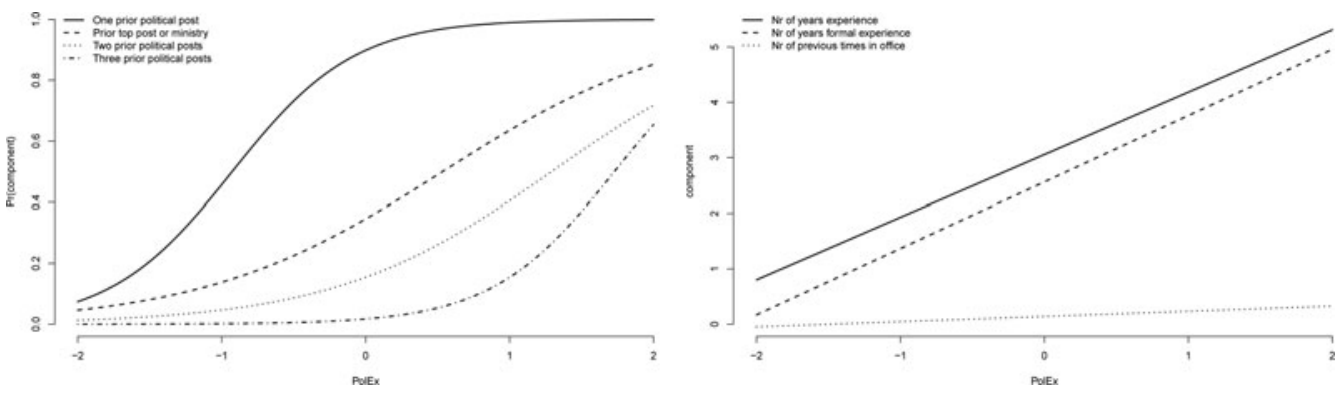

Figure 3. Item response curves

Note: item response curves for all component variables of the latent variable model, with predicted probabilities for binary component variables (left) and linear predictions for count variables (right).

\section{Leaders in 2017}
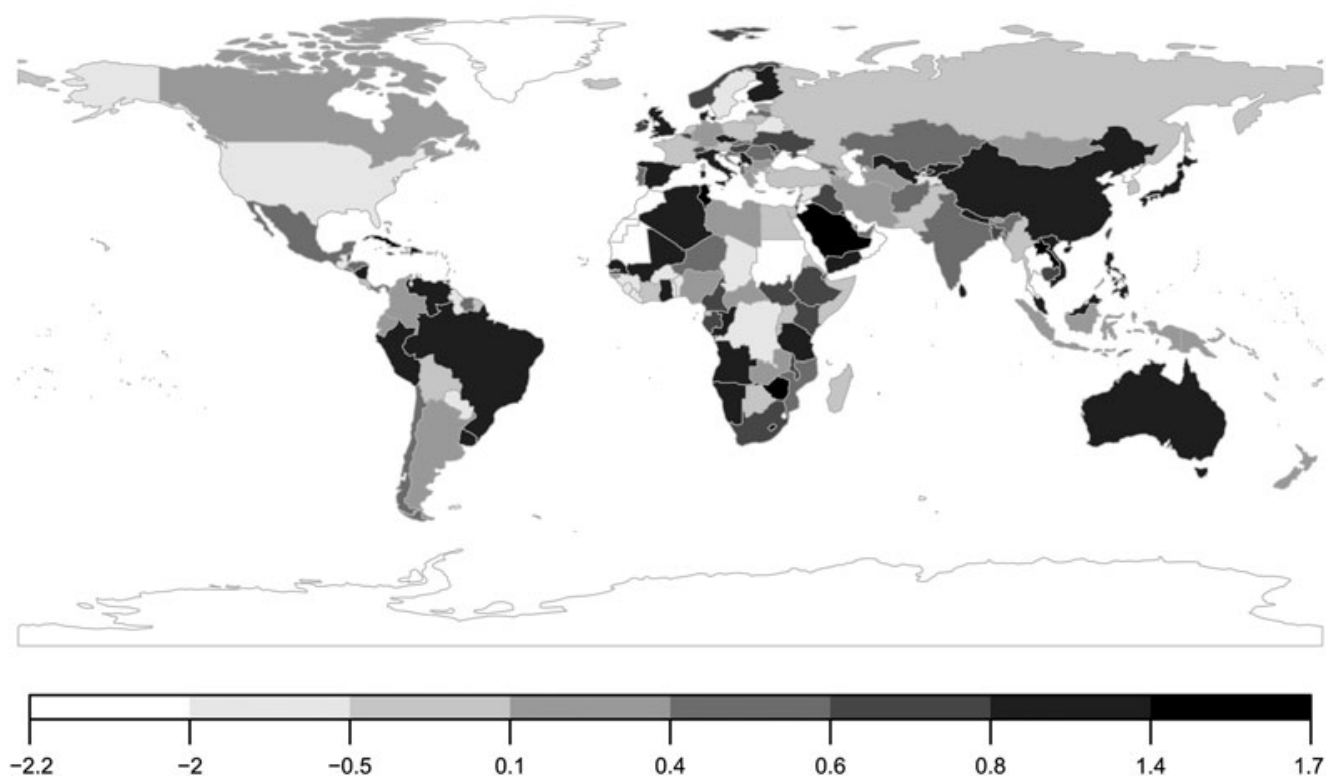

Figure 4. PolEx of world leaders in 2017

Note: PolEx scores from the time of entry into office of incumbent leaders in office on 31 December 2017. 


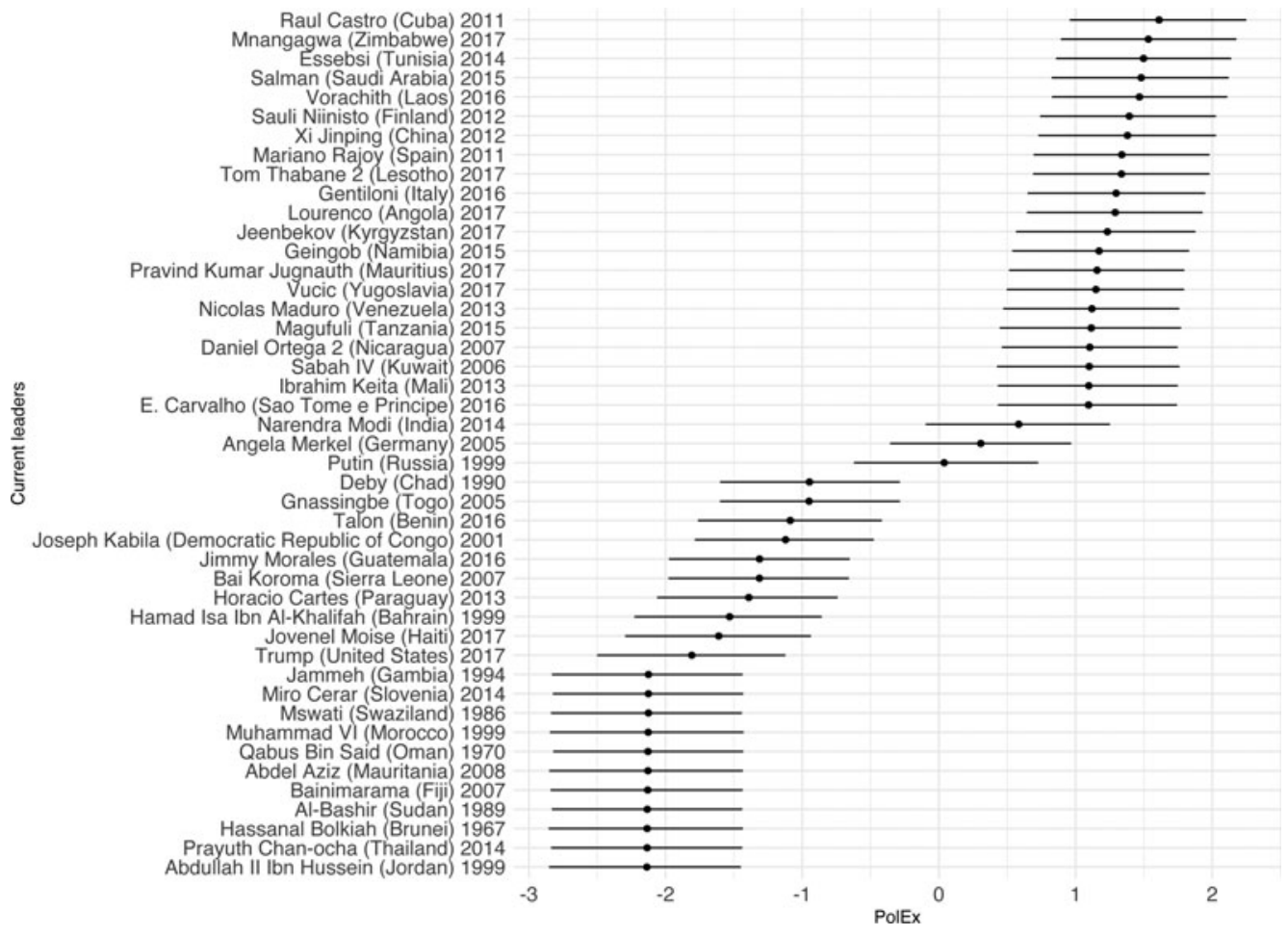

Figure 5. PolEx estimates for selected leaders

Note: average PolEX scores for the 12 per cent least, and 12 per cent most experienced leaders currently in office, with 95 per cent equal tailed credible intervals. In addition, the plot includes Trump, Xi, Putin, Modi and Merkel. Years refer to entry in office.

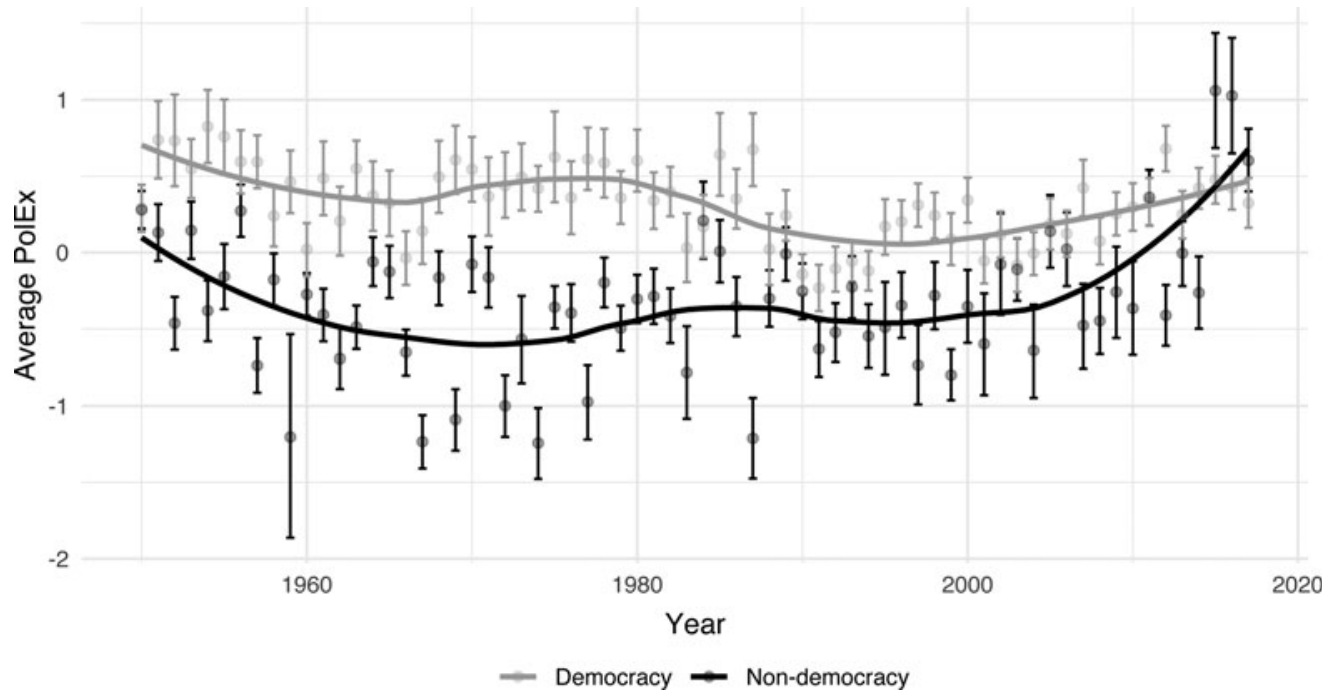

Figure 6. Average PolEx of political leaders, 1950-2017

Note: average value PolEx, at the time of entering office, with 95 per cent equal tailed credible intervals and smoothened curves. 
replaced with a smaller gap in this century as dictatorships came to recruit more experienced leaders, finally closing the gap in recent years. ${ }^{5}$ If democratic leadership becomes relatively less experienced, democracies may find themselves at a disadvantage in settings where leadership matters, such as in international diplomacy.

\section{Conclusions}

Current scholarship has gone beyond the 'leaders matter' argument to examine exactly which leader characteristics and experience matter for survival in office (Yu and Jong-A-Pin 2016), postoffice employment (Baturo 2017) or conflict behaviour (Horowitz, McDermott and Stam 2005). Empirical scholars can now rely on the PolEx score to investigate whether leaders' experience affects policy outcomes. A nebulous and unobservable variable such as political experience is difficult to measure, particularly across regime types. Our prior-experience approach draws on a new data set on nearly 2,000 national leaders to estimate PolEx, a latent experience score. Measurement equivalence across democratic and non-democratic regimes is established by demonstrating the high correlation between latent scores whether estimated jointly or separately by regime type (see Appendix Section 3.1). We establish that democracies tend to select more experienced leaders than non-democracies, but that this distinction has diminished over time.

Supplementary material. Online appendices are available at https://doi.org/10.1017/S0007123421000107.

Data availability statement. The data for the estimation of the model, as well as the resulting estimated PolEx scores and their 95 per cent equal tailed credible intervals can be found in Harvard Dataverse at: https://doi.org/10.7910/DVN/NRC1ZD.

Acknowledgements. We would like to thank the editor and anonymous reviewers, as well as Matthew Kerby, Iain McMenamin, Michael Horowitz, Julia Gray, and the late Robert Elgie for their helpful comments and advice. This article was presented at the General Conference of the European Consortium for Political Research, Hamburg, 2018, and we are grateful for the excellent feedback at the conference. We also thank Jonathan Arlow for excellent research assistance.

Financial support. We acknowledge the receipt of Dublin City University Enhancing Performance Award.

\section{References}

Bak D and Palmer G (2010) Testing the Biden hypotheses: leader tenure, age, and international conflict. Foreign Policy Analysis 6(3), 257-273.

Baturo A (2016) Cursus honorum: personal background, careers and experience of political leaders in democracy and dictatorship - new data and analyses. Politics and Governance 4(2), 138-157.

Baturo A (2017) Democracy, development, and career trajectories of former political leaders. Comparative Political Studies 50(8), 1023-1054.

Baturo A and Elkink J (2021) Replication data for: What countries select more experienced leaders? https://oi.org/10.7910/ DVN/NRC1ZD, Harvard Dataverse, V1, UNF:6:sH3doSLVpnd+5mL3/qkFEg== [fileUNF]

Besley T and Reynal-Querol M (2011) Do democracies select more educated leaders? American Political Science Review 105(3), 552-566.

Carpenter B et al. (2017) Stan: a probabilistic programming language. Journal of Statistical Software 76(1), 1-32.

Clinton J, Jackman S and Rivers D (2004) The statistical analysis of roll call voting: a unified approach. American Political Science Review 98, 355-370.

Curtis RF and Jackson EF (1962) Multiple indicators in survey research. American Journal of Sociology 68(2), $195-204$.

Diamantopoulos A and Winklhofer HM (2001) Index construction with formative indicators: an alternative to scale development. Journal of Marketing Research 38(2), 269-277.

Englund W (2016) The roots of the hostility between Putin and Clinton. The Washington Post, 28 July.

Ewing R (2003) Hu Jintao: the making of a Chinese general secretary. The China Quarterly 173, 17-34.

Gelpi C and Grieco JM (2001) Attracting trouble: democracy, leadership tenure, and the targeting of militarized challenges, 1918-1992. Journal of Conflict Resolution 45(6), 794-817.

\footnotetext{
${ }^{5}$ The Appendix contains additional robustness checks on the estimation of PolEx and the finding regarding democracies and non-democracies.
} 
Glockner-Rist A and Hoijtink H (2003) The best of both worlds: factor analysis of dichotomous data using item response theory and structural equation modeling. Structural Equation Modeling 10(4), 544-565.

Horowitz M, McDermott R and Stam AC (2005) Leader age, regime type, and violent international relations. Journal of Conflict Resolution 49(5), 661-685.

Potter P (2007) Does experience matter? American presidential experience, age, and international conflict. Journal of Conflict Resolution 51(3), 351-378.

Quinn K (2004) Bayesian factor analysis for mixed ordinal and continuous responses. Political Analysis 12, 338-353.

Sartori G (1970) Concept misformation in comparative politics. American Political Science Review 64(4), $1033-1053$.

Treier S and Jackman S (2008) Democracy as a latent variable. American Journal of Political Science 52(1), $201-217$.

Yu S and Jong-A-Pin R (2016) Political leader survival: does competence matter? Public Choice 166, 113-142.

Cite this article: Baturo A, Elkink JA (2022). What Countries Select More Experienced Leaders? The PolEx Measure of Political Experience. British Journal of Political Science 52, 1455-1464. https://doi.org/10.1017/S0007123421000107 